\title{
Relationship between circulating testosterone and emotional behavior in rats
}

\author{
Olanrewaju Akinloye Oyekunle ${ }^{1}$, Goke Francis Ibironke ${ }^{2}$, and Oluwole Adebayo Opabunmi ${ }^{1}$ \\ 1 - Ladoke Akintola University of Technology, Ogbomosho, OY, Nigeria \\ 2 - University of Ibadan, Ibadan, OY, Nigeria
}

\begin{abstract}
The experiment was aimed at investigating the relationship between reduced circulating/endogenous testosterone occasioned by orchiectomy and emotional behavior using the open field test. Eighteen male Wistar rats were randomly selected and classified into two groups: orchiectomized and nonorchiectomized. Orchiectomy was carried out by simple sham surgery. After recovery from orchiectomy, plasma testosterone was determined in both groups after which each animal was observed in the open-field for neurobehavioral activities. The result showed a significant $(p<0.05)$ reduction in plasma testosterone concentration as well as the frequencies of novelty-induced neurobehaviors scored in the open field arena in the orchiectomized group when compared with the nonorchiectomized group. Results indicated that a reduction in circulating testosterone exerts behavioral deficits in orchiectomized animals in the form of fear imposed by exposure to a novel environment resulting in fewer activities. This observation was confirmed by the presence of testosterone receptors in specific brain areas associated with behavioral modulation. We therefore conclude that circulating testosterone could be one of the endogenous mechanisms responsible for coping with fear induced by exposure to a novel environment. Keywords: orchiectomy; testosterone; open field; fear; neurobehavior; amygdala.
\end{abstract}

Received 5 January 2012; received in revised form 16 April 2012; accepted 6 June 2012. Available online 29 June 2012.

\section{Introduction}

Testosterone is one of the major sex hormones produced by the body, occurring in both males and females. In males, it is produced mainly by the Leydig cells of the testes, whereas the ovaries and placenta produce it in females. The adrenal cortex also secretes it in both sexes (Mazur \& Booth, 1998). Apart from being involved in the development of secondary sexual characteristics in males, it is also of special interest in the study of socioemotional and economic behavior because it influences the brain in archetypical situations such as fight, flight, mating, and struggle for status (Coates, 2010; Eisenegger, Haushofer, \& Fehr, 2011). Several studies investigated the association between steroid

Olanrewaju Akinloye Oyekunle and Oluwole Adebayo Opabunmi, Department of Physiology, College of Health Sciences, Ladoke Akintola University of Technology, P.M.B. 4000, Ogbomoso, Oyo State, Nigeria. Goke Francis Ibironke, Department of Physiology, College of Medicine, University of Ibadan, Ibadan, Nigeria. Correspondence regarding this article should be directed to: O.A. Oyekunle, Department of Physiology, College of Health Sciences, Ladoke Akintola University of Technology, P.M.B. 4000, Ogbomoso, Oyo State, Nigeria. Phone: 234803074 2928. E-mail: oaoyekunle@ lautech.edu.ng hormones and neurobehavior in both mammals and other animal species (Brown, 1998; Gahr, 1990). Steroid hormones are widely accepted to modulate animal behavior through indirect actions on neurotransmission in the central nervous system (Hayden-Hixton \& Ferris, 1991). This notion of behavioral modulation by steroid hormones is based on the fact that steroid hormone receptors are widely distributed in vital brain areas that modulate emotional behaviors including the hippocampus, amygdala, and prefrontal cortex (Verma \& Moghaddam 1996; Zahrt, Taylor, Mathew, \& Arnsten, 1997). Testosterone has been implicated in the modulation of some behaviors such as aggression (van Honk et al., 2001; van Honk, Schutter, Hermans, Putman, Tuiten, \& Koppeschaar, 2004) and fear (van Honk, Peper, \& Schutter, 2005) in both humans and experimental animals. Previous reports have firmly established the fear-reducing properties of testosterone, especially exogenously administered testosterone (Aikey, Nyby, Anmuth, \& James, 2002; Aleman, Bronk, Kessels, Koppeschaar, \& van Honk, 2004; Berridge, 2003; Boissy \& Bouissou, 1994). Fear as an index of emotional behavior is a life-saving emotional state that anticipates and adapts to danger (Gallagher \& Holland, 1994). However, through multiple genetic, developmental, and environmental factors, the adaptive 
properties of fear can go awry (Charney, 2004; Gross \& Hen, 2004), leading to aggression or destruction. The destructive value of excess fear has been emphasized in both animal and human models of psychopathology (LeDoux, 1996; Lang, Davis, \& Öhman, 2000). This behavior is often exhibited when the fear circuits of the brain become hyperexcitable (Coplan \& Lydiard, 1998; Tilfors et al., 2001). The neurobiological mechanism thought to be importantly involved in these fear circuits is the endocrine-neuroendocrine amygdala cascade where testosterone is a key component (Corodimas, LeDoux, Gold, \& Schulkin, 1994; Schulkin, Gold, \& McEwen, 1998). The present study therefore explored the relationship between reduced circulating/ endogenous testosterone induced by orchiectomy and fearful behavior in the open field test.

\section{Methods}

\section{Animal handling}

Eighteen mature male Wistar rats (200-250 g) were used for the study. Animals were housed in the preclinical animal house of the College of Health Sciences, Ladoke Akintola University of Technology, Ogbomoso. Animals were randomly assigned to two groups: orchiectomized and nonorchiectomized $(n=9$ per group). They were maintained under standard laboratory conditions and a $12 \mathrm{~h} / 12 \mathrm{~h}$ light/dark cycle at $23 \pm 2^{\circ} \mathrm{C}$ with free access to food and water throughout the experiment. All experimental procedures were approved by the institutional animal ethics committee.

\section{Chemicals}

Ketamine was obtained from Sigma (St. Louis, MO, USA). The other chemicals, including methylated spirit and penicillin, were analytical-grade and procured locally.

\section{Orchiectomy}

Bilateral orchiectomy was performed as described by Svensson, Berntsson, Engel, \& Soderpalm (2000). Under ketamine anesthesia (50 $\mathrm{mg} / \mathrm{kg}$, i.p.), a small surgical incision was made in the center of the scrotum. Each testicle was exposed through the surgical orifice. The ductus deferens and main arteries and veins were isolated, ligated, and severed, allowing the testicle and epididymis to be removed. The incision was then closed, sutured, and swabbed with povidone-iodine solution. The postoperative procedure was implemented, and the rats were housed in separate cages and allowed free access to food and water for approximately 4 weeks before the experiment.

\section{Determination of plasma testosterone levels}

Blood samples $(2.5 \mathrm{ml})$ were collected through the saphenous vein with partial restraint in orchiectomized and nonorchiectomized animals $24 \mathrm{~h}$ prior to the open field test. The samples were centrifuged at $3000 \mathrm{rpm}$ for
3-5 min using a Uniscope laboratory centrifuge (Model SM800B, Surgifriend Medicals, Essex, UK). Plasma testosterone levels were determined using a standard enzyme-linked immunosorbent assay as described by Tietz (1995) and the Microwell Method (Dialab, Wiener Neudorf, Austria) with parallel measurements in the respective calibrators attached to the kit.

\section{Neurobehavioral study: open field test}

The open field apparatus was constructed of square plywood $(96 \times 96 \mathrm{~cm})$ with $60 \mathrm{~cm}$ high walls. One of the walls was made of Plexiglas to facilitate an unobstructed view of the animal in the box. The floor was painted green and divided into 16 squares by parallel and intersecting white lines (Bhattacharya \& Satyan, 1997). The rats were individually placed in one corner of the open field, and the following behaviors were visually scored for $5 \mathrm{~min}$ in both orchiectomized and nonorchiectomized rats: locomotion, rearing, and grooming. The maze was located in a $1.8 \times 4.6 \mathrm{~m}$ test room and lit by a $60 \mathrm{~W}$ red lamp for background lighting.

The rats were carried to the test room in their home cages and handled by the base of their tails at all times. The rats were placed in the center or one of the four corners of the open field and allowed to explore the apparatus for $5 \mathrm{~min}$. After the 5 -min test, the rats were returned to their home cages, and the open field was cleaned with $70 \%$ ethyl alcohol and permitted to dry between tests. To assess habituation to the novelty of the arena, the rats were exposed to the apparatus for 5 min on 2 consecutive days. The following behaviors were scored: total locomotor activity (i.e., the frequency with which the animal crossed the grid lines with all four paws and the frequency of rearing were taken as an index of locomotor activity; Walsh \& Cummins, 1976), rearing (i.e., the frequency with which the animal stood on its hind legs in the maze; Brown, Corey, \& Moore, 1999), and grooming (i.e., the frequency of face washing and paw licking while stationary in the maze; Brown et al., 1999).

\section{Statistical analysis}

Data are expressed as the mean \pm standard error of the mean and analyzed using Student's $t$-test. Values of $p<.05$ were considered statistically significant.

\section{Results}

\section{Testosterone}

The statistical analysis of plasma testosterone levels revealed a significant reduction of testosterone levels in orchiectomized animals $(p<.05)$ compared with the nonorchiectomized group. Orchiectomy does not completely abolish the secretion of androgens because they can be secreted from sources other than the testes, such the adrenal organ. This explains the slight amount of the hormone detected in the orchiectomized group. 
Table1. Effect of orchiectomy on plasma testosterone, total locomotion, rearing, and grooming

\begin{tabular}{lllll}
\hline Group & $\begin{array}{l}\text { Plasma testosterone } \\
(\mathbf{n m} / \mathbf{L})\end{array}$ & Total locomotion & $\begin{array}{l}\text { Rearing } \\
\text { frequency/5 min }\end{array}$ & $\begin{array}{l}\text { Grooming } \\
\text { frequency/5 min }\end{array}$ \\
\hline Nonorchiectomized (control) & $21.55 \pm .2$ & $82 \pm 1.8$ & $39 \pm 2.4$ & $44.4 \pm 2.9$ \\
Orchiectomized (experimental) & $3.25 \pm .2^{*}$ & $75.5 \pm 1.3^{*}$ & $32.2 \pm 2.1^{*}$ & $20.4 \pm 2.3^{*}$ \\
\hline
\end{tabular}

Data are expressed as mean $\pm \operatorname{SEM}(n=9$ per group)

$* p<.05$ compared with nonorchiectomized group

\section{Locomotion, rearing, and grooming}

The open field results showed a significant reduction of the number of grid lines crossed and frequency with which the animals stood on their hindlimbs during the 5 -mintest in the orchiectomized group compared with the nonorchiectomized group $(p<.05)$. Paw licking and face washing (i.e., grooming) also significantly decreased $(p<.05)$ in the orchiectomized group compared with the nonorchiectomized group.

\section{Discussion}

The open field test (Hall, 1934; Hall \& Ballenchey, 1932) provides simultaneous measures of locomotion, exploration, and anxiety. The number of lines crossed and frequency of rearing are usually used as measures of locomotor activity but also reflect exploration and anxiety. A high frequency of these behaviors indicates increased locomotion and exploration and/or lower levels of anxiety (Walsh \& Cummins, 1976). The number of central square entries and duration of time spent in the central square are measures of exploratory behavior and anxiety. A high frequency or duration of these behaviors indicates high exploratory behavior and low anxiety levels. However, the number of grid lines crossed and frequency of rearing and grooming were adopted as indices of anxiety/fear in the present study and have been documented as reliable and valid measures of emotional behavior (Ivinskis, 1968; Prescott, 1970).

Table 1 shows that orchiectomized animals exhibited a significant reduction of exploratory behavior, indicating elevated fear or increased anxiety, and this observation was consistent with previous open field studies (Hall, 1934; Archer, 1973; Blanchard, Griebel,\& Blanchard, 2001). Several studies have shown that elevated testosterone level reduce anxiety-like or fearful behavior in rodents in several behavioral paradigms (Fernandez-Guasti \& Martinez-Mota, 2005; Frye \& Seliga 2001; Eisenegger et al., 2011). Therefore, an inverse relationship appears to exist between testosterone levels and exhibition of anxiety-like or fearful behavior. However, the neural mechanism remains unknown. The fear-reducing properties of elevated testosterone have been shown to be $\gamma$-aminobutyric acid $\mathrm{A}\left(\mathrm{GABA}_{\mathrm{A}}\right)$ receptor-dependent in the amygdala (Hermans, Ramsey, Tuiten, \& van Honk, 2004; Hermans, Putman, Baas, Koppeschaar, \& Honk, 2006), whereas the opposite relationship is unclear but may also be integrated via various dopaminergic systems in the hippocampus, amygdala, and other parts of the mesocortical system. The presence of androgen receptors in the hippocampus, amygdala, and parts of the mesocortical system in mammals lends credence to this notion (Choate \& Resko, 1996; Greco, Edwards, Michael, \& Clancy, 1998; Resko, Connolly, Roselli, Abdelgadir, \& Choate, 1993; Clancy, Bonsall, \& Michael, 1992). These parts of the brain are known to influence emotional aspects of behavior. Lesions and inactivation of these areas have been associated with some symptoms of depression and an inability to cope with fear (Krishnan \& Nestler, 2010; Tamminga, 2010; Kritzer \& Creutz, 2008). In the present study there was a reduction of circulating testosterone-induced behavioral deficits in orchiectomized animals, resulting in less activity in the form of fear imposed by exposure to a novel environment. Therefore, not only perturbation of the prefrontal dopaminergic system induces behavioral deficits, but reduced circulating testosterone can also induce such deficits as shown by this study. Therefore, we conclude that circulating testosterone may be one endogenous mechanism responsible for coping with fear induced by exposure to a novel environment.

\section{References}

Aikey, J. L., Nyby, J. G., Anmuth, D. M., \& James, P. J. (2002). Testosterone rapidly reduces anxiety in male house mice (Musmusculus). Hormones and Behavior, 42, 448-460.

Aleman, A., Bronk, E., Kessels, R. P. C., Koppeschaar, H. P. F., \& van Honk, J. (2004). A single administration of testosterone improves visuospatial ability in young women. Psychoneuroendocrinology, 29, 612-617.

Archer, J. (1973). Tests for emotionality in rats and mice: A review. Animal Behavior, 21, 205-235.

Berridge, K. C. (2003). Comparing the emotional brains of humans and other animals. In: R. J. Davidson, K. R. Scherer, \& H. H. Goldsmith (Eds.). Handbook of affective sciences (pp. 25-51). New York: Oxford University Press.

Bhattacharya, S. K., \& Satyan, K. S. (1997). Experimental methods for the evaluation of psychotropic agents in rodents: I. Anti-anxiety agents. Indian Journal of Experimental Biology, 35, 565-575.

Blanchard, D. C., Griebel, G., \& Blanchard, R. J. (2001). Mouse defensive behaviors: Pharmacological and behavioral assays for anxiety and panic. Neuroscience and Biobehavioral Reviews, 25, 205-218.

Boissy, A., \& Bouissou, M. F. (1994). Effects of androgen treatment on behavioral and physiological responses of heifers to feareliciting situations. Hormones and Behavior, 28, 66-83.

Brown, R. E., Corey, S. C., \& Moore, A. K. (1999).Differences in measures of exploration and fear in $\mathrm{MHC}$-congenic $\mathrm{C} 57 \mathrm{BL} / 6 \mathrm{~J}$ and B6-H-2K mice. Behavior Genetics, 29, 263-271.

Brown, T. R. (1998). Steroid hormones overview. In: E. Knobil, \& J. D. Neill (Eds.), Encyclopedia of reproduction: Volume 4. Pro - Z (pp. 634-644). San Diego: Academic Press.

Charney, D. S. (2004). Psychobiological mechanisms of resilience and vulnerability: Implications for successful adaptation to extreme stress. American Journal of Psychiatry, 161, 195-216. 
Choate, J. V., \& Resko, J. A. (1996).Effects of androgen on brain and pituitary androgen receptors and $\mathrm{LH}$ secretion of male guinea pigs. Journal of Steroid Biochemistry and Molecular Biology,59, 315-322.

Clancy, A. N., Bonsall, R. W., \&Michael, R. P. (1992). Immunohistochemical labeling of androgen receptors in the brain of rat and monkey. Life Sciences, 50, 409-417.

Coates, J. M. (2010). From molecule to market: Steroid hormones and financial risk-taking. Philosophical Transactions of the Royal Society of London: B. Biological Sciences, 365, 331-343.

Coplan, J. D., \& Lydiard, R. B. (1998). Brain circuits in panic disorder Biological Psychiatry, 44, 1264-1276.

Corodimas, K. P., LeDoux, J. E., Gold, P. W., \& Schulkin, J. (1994) Corticosterone potentiation of conditioned fear in rats. Annals of the New York Academy of Sciences, 746, 392-393.

Eisenegger, C., Haushofer, J., \& Fehr, E. (2011). The role of testosterone in social interaction. Trends in Cognitive Sciences, 15, 263-271.

Fernandez-Guasti, A., \& Martinez-Mota, L. (2005). Anxiolytic-like actions of testosterone in the burying behavior test: Role of androgen and GABA-benzodiazepine receptors. Psychoneuroendocrinology, 30, 762-770.

Frye, C. A., \& Seliga, A. M. (2001). Testosterone increases analgesia, anxiolysis, and cognitive performance of male rats. Cognive, Affective and Behavioral Neuroscience, 1, 371-381.

Gahr, M. (1990). Localization of androgen receptors and estrogen receptors in the same cells of the songbird brain. Proceedings of the National Academy of Sciences of the United States of America, 87, 9445-9448.

Gallagher, M., \& Holland, P. C. (1994). The amygdala complex: multiple roles in associative learning and attention. Proceedings of the National Academy of Sciences of the United States of America, 91, 11771-11776.

Greco, B., Edwards, D. A., Michael, R. P., \& Clancy, A. N. (1998). Androgen receptors and estrogen receptors are colocalized in male rat hypothalamic and limbic neurons that express Fos immunoreactivity induced by mating. Neuroendocrinology, 67, 18-28.

Gross, C., \& Hen, R. (2004). The developmental origins of anxiety. Nature Reviews Neuroscience, 5, 545-552.

Hall, C. S. (1934). Emotional behavior in the rat: I. Defecation and urination as measures of individual differences in emotionality. Journal of Comparative and Physiological Psychology, 18, 385403.

Hall, C. S., \& Bellenchey, E. L. (1932). A study of rat's behaviour in a field: A contribution to method in comparative psychology. University of California Publications in Psychology, 6, 1-12.

Hayden-Hixson, D. M., \& Ferris, C. F. (1991).Steroid-specific regulation of agonistic responding in the anterior hypothalamus of male hamsters. Physiology and Behavior, 50, 793-799.

Hermans, E. J., Putman, P., Baas, J. M., Koppeschaar, H. P., \& Honk, J. V. (2006). A single administration of testosterone reduces fearpotentiated startle in humans. Biological Psychiatry, 59, 872-874.

Hermans, E. J., Ramsey, N., Tuiten, A., \& van Honk, J. (2004). The amygdala and anger: responses to angry facial expressions after administration of a single dose of testosterone. Human Brain Mapping, 23, S188.

Ivinskis, A. (1968). The reliability of behavioural measures obtained in the open field. Australian Journal of Psychology, 20, 173-177.

Krishnan, V., \& Nestler, E. J. (2010). Linking molecules to mood: New insight into the biology of depression. American Journal of Psychiatry, 167, 1305-1320.
Kritzer, M. F., \& Creutz, L. M. (2008). Region and sex differences in constituent dopamine neurons and immunoreactivity for intracellular estrogen and androgen receptors in mesocortical projections in rats. Journal of Neuroscience, 28, 9525-9535.

Lang, P. J., Davis, M., \& Öhman, A. (2000). Fear and anxiety: Animal models and human cognitive psychophysiology. Journal of Affective Disorders, 61, 137-159.

LeDoux, J. E. (1996). The emotional brain: The mysterious underpinnings of emotional life. New York: Simon \& Schuster.

Mazur, A., \& Booth, A. (1998). Testosterone and dominance in men. Behavioral and Brain Sciences, 21, 353-363, discussion 363-397.

Prescott, R. (1970). Some behavioural effects of variables which influence "general level of activity" of rats.Animal Behaviour, 18, 791-796.

Resko, J. A., Connolly, P. B., Roselli, C. E., Abdelgadir, S. E., \& Choate, J.V. (1993). Selective activation of androgen receptors in the subcortical brain of male cynomologus macaques by physiological hormone levels and its relationshipto androgendependent aromatase activity. Journal of Clinical Endocrinology and Metabolism, 76, 1588-1593.

Schulkin, J., Gold, P. W., \& McEwen, B. S. (1998). Induction of corticotropin-releasing hormone gene expression by glucocorticoids: Implication for understanding the states of fear and anxiety and allostatic load. Psychoneuroendocrinology, 23, 219-243.

Svensson, A. I., Berntsson, A., Engel, J. A., \& Soderpalm, B. (2000). Disinhibitory behavior and $\mathrm{GABA}_{\mathrm{A}}$ receptor function in serotonin-depleted adult male rats are reduced by gonadectomy. Pharmacology Biochemistry and Behavior, 67, 613-620.

Tamminga, C. A. (2010). The hippocampal formation in schizophrenia.American Journal of Psychiatry, 167, 1178-1193.

Tietz, N. W. (1995). Clinical guide to laboratory tests, 3rd edition (p. 578-580). Philadelphia: W. B. Saunders.

Tillfors, M., Furmark, T., Marteinsdottir, I., Fischer, H., Pissiota, A., Langstrom, B., \& Fredrikson, M. (2001). Cerebral blood flow in subjects with social phobia during stressful speaking tasks: a PET study. American Journal of Psychiatry, 158, 1220-1226.

van Honk, J., Peper, J. S., \&Schutter, D. J. (2005). Testosterone reduces unconscious fear but not consciously experienced anxiety: Implications for the disorders of fear and anxiety. Biological Psychiatry, 58, 218-225.

van Honk, J., Schutter, D. J. L. G., Hermans, E. J., Putman, P., Tuiten, A., \& Koppeschaar, H. (2004). Testosterone shifts the balance between sensitivity for punishment and reward in healthy young women. Psychoneuroendocrinology, 29, 937-943.

van Honk, J., Tuiten, A., Hermans, E., Putman, P., Koppeschaar, H., Thijssen, J., Verbaten, R., \& van Doornen, L. (2001). A single administration of testosterone induces cardiac accelerative responses to angry faces in healthy young women. Behavioral Neuroscience, 115, 238-242.

Verma, A., \& Moghaddam, B. (1996). NMDA receptor antagonists impair prefrontal cortex function as assessed via spatial delayed alternation performance in rats: Modulation by dopamine. Journal of Neuroscience, 16, 373-379.

Walsh, R. N., \& Cummins, R. A. (1976). The open-field test: A critical review. Psychological Bulletin, 83, 482-504.

Zahrt, J., Taylor, J. R., Mathew, R. G., \& Arnsten, A. F. (1997). Supranormal stimulation of $\mathrm{D}_{1}$ dopamine receptors in the rodent prefrontal cortex impairs spatial working memory performance. Journal of Neuroscience, 17, 8528-8535. 